\title{
Oral health of Iranian children in 2004: a national pathfinder survey of dental caries and treatment needs
}

\author{
S. Bayat-Movahed, ${ }^{1}$ H. Samadzadeh, ${ }^{2}$ L. Ziyarati, ${ }^{2}$ N. Memary, ${ }^{2}$ R. Khosravi ${ }^{3}$ and P.S. Sadr-Eshkevari ${ }^{4}$
}

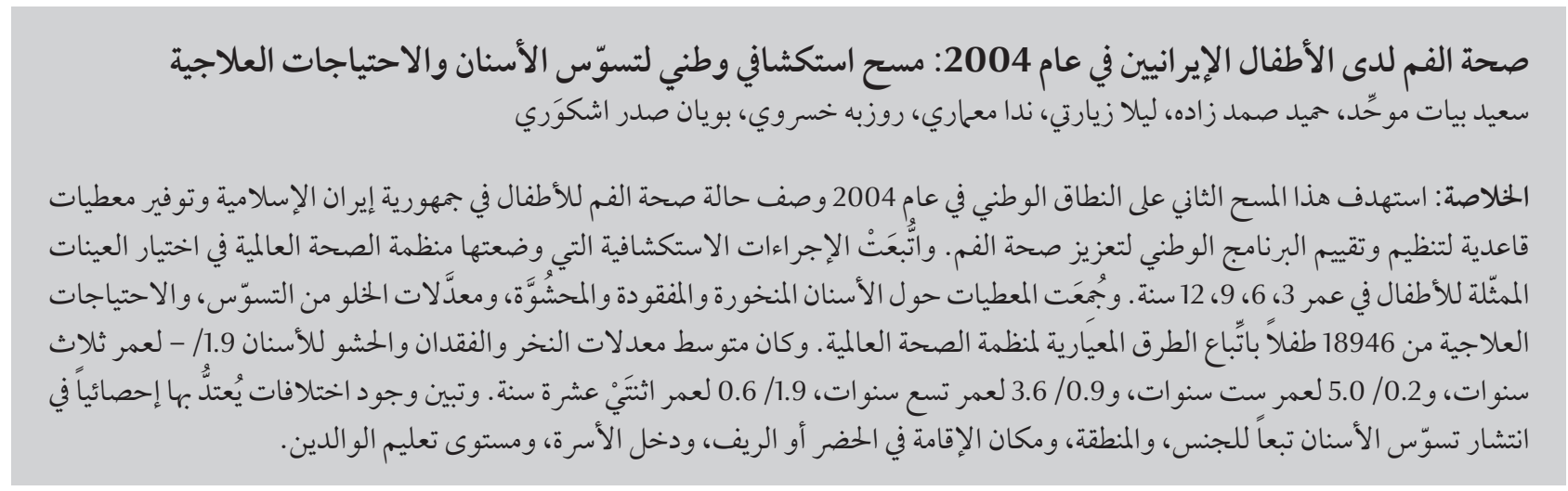

ABSTRACT A second nationwide survey in 2004 aimed to describe the oral health status of children in the Islamic Republic of Iran and to provide baseline data for the organization and evaluation of the national oral health promotion programme. WHO pathfinder sampling procedures were used to select representative samples of children aged 3, 6, 9 and 12 years. Data on decayed/missing/filled teeth, caries-free rates and treatment needs were collected from 18946 children using WHO standard methods. The mean dmft/DMFT indices were 1.9/- for 3-year-olds, 5.0/0.2 for 6-year-olds, 3.6/0.9 for 9-year-olds and 0.6/1.9 for 12-year-olds. Significant differences in dental caries prevalence were found according to sex, province, urban/rural residence, family income and parents' level of education.

Santé bucco-dentaire des enfants iraniens en 2004 : une enquête exploratoire nationale sur les caries dentaires et les besoins thérapeutiques

RÉSUMÉ En 2004, une deuxième enquête à l'échelle du pays visait la description de l'état de santé buccodentaire des enfants en République islamique d'Iran et la production de données de référence pour l'organisation et l'évaluation du programme national de promotion de la santé bucco-dentaire. Les procédures d'échantillonnage recommandées par l'OMS dans les enquêtes exploratoires ont été utilisées pour sélectionner des échantillons représentatifs d'enfants âgés de 3, 6, 9 et 12 ans. Les données sur les dents cariées/absentes/ obturées, le taux de dents saines et les besoins thérapeutiques ont été recueillis à partir de 18946 enfants, conformément aux méthodes classiques préconisées par l'OMS. L'indice moyen de dents cariées, absentes ou obturées (dcao pour la première dentition/DCAO pour la dentition permanente) était de 1,9/- pour les enfants de trois ans, de 5,0/0,2 pour les enfants de six ans, de 3,6/0,9 pour les enfants de neuf ans et de 0,6/1,9 pour les enfants de douze ans. Des différences significatives dans la prévalence des caries dentaires ont été observées en fonction du sexe, de la province, du lieu de résidence en milieu urbain ou rural, des revenus familiaux et du niveau d'instruction des parents.

${ }^{7}$ Faculty of Dentistry, Tehran University ofMedical Sciences, Tehran, Islamic Republic of Iran (Correspondence to Bayat-Movahed: swt_f@yahoo.com). ${ }^{2}$ Office of Health, Ministry of Health and Medical Education, Tehran, Islamic Republic of Iran.

${ }^{3}$ Goldman School of Dental Medicine, Division of Oral Biology, University of Boston, Boston, Massachusetts, United States of America.

${ }^{4}$ Dental Section, Farzan Clinical Research Institute, Tehran, Islamic Republic of Iran.

Received: 11/02/09; accepted: 17/06/09 


\section{Introduction}

Rapid development and modernization in the Eastern Mediterranean countries has led to changes in lifestyle and diet that are likely to have an effect on oral health. Poor oral health profoundly affects a person's quality of life $[1,2]$. The dental health care system in the Islamic Republic of Iran is an integrated public health system with a 4-level dental health care system from basic oral health care services in rural health houses and health centres to advanced treatments at university health centres in the bigger cities. More than 13000 dentists practice nationwide (1 dentist:5500 population). There are also about 1200 specialists working in universities and private practices [3].

The oral health status of children is determined by the prevalence of dental caries and an assessment of periodontal health status [4]. The inclusion of the national oral and dental health care programme into the primary health care system of the Islamic Republic of Iran began in 1995 [5]. For the first time at a national level, the oral health department of the Ministry of Health determined the decayed/missing/filled teeth (DMFT) index of 12-year-old Iranian children the same year. The mean DMFT was 2.0, which indicated that the oral health status of this age group could be classified in the low range (mean DMFT 1.2-2.6) compared with other countries worldwide, and this was consistent with the oral health goals set by the World Health Organization (WHO) for 2000, albeit far from the goals set for 2020 [6].

Two years after the establishment of the national oral and dental health care programme, the national students' oral and dental health care programme was introduced which focused on the early school-age groups throughout the country, especially in terms of preventive measures including oral health and diet education. A second national oral health survey was conducted by including the age groups 3,6 and 9 years the same year. The DMFT of 12-year-olds was calculated as 1.5, which showed a dramatic change in the oral health of the Iranian children and supported the effectiveness of the nationwide oral health care programmes $[5,7]$. The survey reported here was conducted in 2004 to evaluate the oral health status and dental care needs of Iranian children aged 3, 6, 9 and 12 years. By comparing these findings with the earlier national survey performed in 1998 and the results of other local surveys on 6- and 9-year-old children during 1998-2004, we aimed to estimate the efficacy of the dental health care programmes in the Islamic Republic of Iran.

\section{Methods}

\section{Study design}

Four age groups of children were selected for this national pathfinder survey of children in 2004: 3 years (the age when the first signs of carious lesions tend to be encountered); 6 years (the age of school entry in the Islamic Republic of Iran); 9 years (the age when the deciduous dentition is almost completely replaced); and 12 years (the age at which children leave primary school and therefore the last age at which a reliable sample could be obtained easily through the school system). The 3-yearold children were those between their 3rd and 4th birthdays, the 6-year-olds between their 6 th and 7 th birthdays, etc. The surveys of 3-and 12-year-olds were carried out from 21 February to 20 April 2004 and of 6-and 9-year-olds from 21 February to 21 May 2004.

\section{Sampling}

For 6- and 9-year-old children, a cluster multistage probability sampling was performed to provide nationally representative data. Based on WHO recommendations for pathfinder national survey methods [8], a population of 300 is sufficient for the study of DMFT.
However, when sampling a population with low DMFT level it is possible to reduce the cluster number to $20(\times 15)$ or at least $12(\times 25)$. Since the DMFT of Iranian 12-year-old children was considered to be low according to the earlier survey, it was decided to reduce the cluster number. On the other hand, 3- and 12-year-olds were studied at the national level and 6- and 9-yearolds were studied at the province level. Therefore sample sizes were optimized for each age group.

The sampling was based on the administrative divisions of the country (28 provinces, including the capital city, Tehran, the main urban centres within each province and small towns or rural areas within each province). The first stage of the design consisted of selecting a sample of 349 primary sampling units (PSUs). Except for the capital, 12 PSUs were selected in each of 27 provinces and 24 PSUs were selected in Tehran (10\% of the national population). A sample of 25 children was selected for each 6- and 9-year-old PSUs. For the 3- and 12-year-old children, 50 clusters were selected based on the population of the provinces and 15 children aged 3 or 12 years were selected in each cluster.

\section{Oral examinations}

Families of the selected children were sent invitation letters to participate in the survey. Oral examinations were performed in the nearest community health centre to the child's house. First a questionnaire was administered to collect demographic data, followed by the clinical examination. A team of dentists trained and calibrated to WHO standards [4] performed all dental examinations. The examiners used front surface mirrors, no. 23 explorers and high-intensity artificial lighting. Data on decayed, missing and filled teeth (primary and deciduous) were recorded, excluding third molars. Trained oral hygienists entered dental examination information into a 1-page dental chart. 
Tooth condition was coded differently for permanent (DMFT) and deciduous teeth $(\mathrm{dmft})$. Dean's index was used to record fluorosis. Treatment needs including single/multiple surface filling, stainless steel crown, fissure sealant, endodontic treatment, and extraction were recorded. Caries-free prevalences were calculated by age group [9-11].

The survey protocol was reviewed and approved by the Ministry of Health and Medical Education and the parents of all survey participants signed informed consent forms. Of the 18950 children sampled 18946 consented to be examined. All children with dental caries were treated at no charge.

\section{Data analysis}

The prevalence of DMFT/dmft was calculated for each age group according to caries risk factors: sex (male versus female), province (27 provinces), and urbanization (rural versus urban). Data were classified and statistically analysed using SPSS, version 10. To compare means and percentages, $t$-tests and $z$ tests were used to detect possible signifcance differences at $\alpha=0.05$.

\section{Results}

\section{Demographic data}

Table 1 summarizes the distribution of the study population in the 4 age groups by sex and urban/rural area of residence.

\section{$\mathrm{dmft} / \mathrm{DMFT}$ indices}

The mean $\mathrm{dmft} / \mathrm{DMFT}$ indices for children in the Islamic Republic of Iran were $1.9 /$ - for 3 -year-olds, 5.0/0.2 for 6-year-olds, 3.6/0.9 for 9-year-olds and 0.6/1.9 for 12-year-olds (Tables 2 and 3).

The prevalence of dental caries for 6-and 9-year-olds varied greatly between different provinces. For instance, in 2004, the $\mathrm{dmft} / \mathrm{DMFT}$ of 6-year-old children ranged from 1.9/0.02 in Hormozgan/ Bushehr provinces to 6.6/0.5 in Ilam/Ardebil provinces. The mean $\mathrm{dmft} / \mathrm{DMFT}$ scores for 9-year-old children ranged from 1.7/0.1 in Bushehr/Hormozgan provinces to 5.1/1.8 in Lorestan/Chaharmahal-o-Bakhtiyari provinces.

\section{3-year-olds}

A total of 750 3-year-olds were examined. The overall mean dmft index was
1.9. Boys had a significantly higher mean dmft $(2.2)$ than girls $(1.6)(P<0.05)$ (Table 2) and the index was higher in children living in urban areas (2.1) than those in rural areas $(1.5)(P<0.05)$. Mean filled teeth $(\mathrm{ft})$, missing teeth $(\mathrm{mt})$ and decayed teeth $(\mathrm{dt})$ scores were $0.05,0.03$ and 1.8 respectively.

The prevalence of caries according to the total $\mathrm{dt}$ of the population showed that the tooth that was most susceptible to caries was the primary mandibular first molar with a left/right incidence of caries of $21.7 \% / 21.9 \%$. The primary mandibular second molar was ranked second with a caries incidence of $17.1 \% / 19.2 \%$ for the lower jaw. The primary mandibular lateral incisors of the lower jaw showed the lowest caries incidence at $0.8 \% / 0.9 \%$.

\section{6-year-olds}

A total of 8725 6-year-olds were examined. The mean $\mathrm{dmft}$ index was 5.0 (Table 2). Girls had a significantly lower mean $\mathrm{dmft}$ than boys (4.6 and 5.3 respectively) $(P<0.05)$. Children living in urban areas had significantly higher dmft index (5.1) than children living in rural areas $(4.8)(P<0.05)$. Dental caries

\begin{tabular}{|c|c|c|c|c|c|c|c|c|c|c|}
\hline \multirow{2}{*}{$\begin{array}{l}\text { Age group } \\
\text { (years) }\end{array}$} & \multirow{2}{*}{$\begin{array}{l}\text { Mean } \\
\text { age } \\
\text { (years) }\end{array}$} & \multicolumn{2}{|c|}{ Male } & \multicolumn{2}{|c|}{ Female } & \multicolumn{2}{|c|}{ Urban } & \multicolumn{2}{|c|}{ Rural } & \multirow{2}{*}{$\begin{array}{l}\text { Total } \\
\text { No. }\end{array}$} \\
\hline & & No. & $\%$ & No. & $\%$ & No. & $\%$ & No. & $\%$ & \\
\hline 3 & 3.5 & 399 & 53 & 351 & 47 & 465 & 62 & 285 & 38 & 750 \\
\hline 6 & 6.8 & 4697 & 54 & 4028 & 46 & 4825 & 55 & 3900 & 45 & 8725 \\
\hline 9 & 9.5 & 4640 & 53 & 4083 & 47 & 4849 & 56 & 3874 & 44 & 8723 \\
\hline 12 & 12.4 & 378 & 50 & 370 & 50 & 465 & 62 & 283 & 38 & 748 \\
\hline
\end{tabular}

\begin{tabular}{|c|c|c|c|c|c|c|c|c|}
\hline \multirow{2}{*}{$\begin{array}{l}\text { Age group } \\
\text { (years) }\end{array}$} & \multirow{2}{*}{$\begin{array}{c}\text { No. } \\
\text { sampled }\end{array}$} & \multicolumn{7}{|c|}{ Mean (SD) dmft } \\
\hline & & Total & Boys & Girls & Significance & Rural & Urban & Significance \\
\hline 3 & 750 & $1.9(0.2)$ & $2.2(0.3)$ & $1.6(0.3)$ & $P<0.05$ & $1.5(0.3)$ & $2.1(0.3)$ & $P<0.05$ \\
\hline 6 & 8725 & $5.0(0.0)$ & $5.3(0.0)$ & $4.6(0.0)$ & $P<0.05$ & $4.8(0.0)$ & $5.1(0.0)$ & $P<0.05$ \\
\hline 9 & 8723 & $3.6(0.0)$ & $3.9(0.0)$ & $3.3(0.0)$ & $P<0.05$ & $3.5(0.0)$ & $3.7(0.0)$ & $P<0.05$ \\
\hline 12 & 748 & - & - & - & - & - & - & - \\
\hline
\end{tabular}

$S D=$ standard deviation. 


\begin{tabular}{|c|c|c|c|c|c|c|c|c|}
\hline \multirow{2}{*}{$\begin{array}{l}\text { Age group } \\
\text { (years) }\end{array}$} & \multirow{2}{*}{$\begin{array}{c}\text { No. } \\
\text { sampled }\end{array}$} & \multicolumn{7}{|c|}{ Mean (SD) DMFT } \\
\hline & & Total & Boys & Girls & Significance & Rural & Urban & Significance \\
\hline 3 & 750 & - & - & - & - & & & - \\
\hline 6 & 8725 & $0.2(0.0)$ & $0.4(0.0)$ & $0.5(0.0)$ & NS & $0.2(0.0)$ & $0.3(0.0)$ & NS \\
\hline 9 & 8723 & $0.9(0.0)$ & $0.9(0.0)$ & $0.9(0.0)$ & NS & $0.8(0.0)$ & $1.0(0.0)$ & NS \\
\hline 12 & 748 & $1.9(0.2)$ & $1.7(0.2)$ & $2.0(0.2)$ & $P<0.05$ & $1.7(0.2)$ & $1.9(0.2)$ & $P<0.05$ \\
\hline
\end{tabular}

$S D=$ standard deviation $; N S=$ not significant.

comprised the biggest component of $\mathrm{dmft}$ for 6-year-old children: $\mathrm{dt}, \mathrm{mt}$ and ft were $4.4,0.4$ and 0.2 respectively.

The overall mean DMFT index was 0.2 (Table 3). There were no significant differences by sex or rural/urban area. Dental caries were again the biggest portion of DMFT index in 6-year-olds; for every 100 children, an average of 8 fillings, 2 missing and 20 dental caries were detected in their permanent dentition.

The primary first molar was the most decayed among primary teeth with a left/right caries prevalence of $61.0 \% / 62.3 \%$ for the lower jaw and $43.4 \% / 58.2 \%$ for the upper jaw. The primary second molar had the greatest caries prevalence in the lower jaw with a 54.6\%/54.9\% rate. Among permanent teeth, the lower first molar showed the highest rate of caries with 7.1\%/7.5\% in the lower jaw. The incisors and the canines had the lowest rate of caries among permanent teeth at this age.

\section{9-year-olds}

A total of 8723 9-year-olds were examined. Themean dmftindexin 9-year-olds was 3.6 and there were no significant differences between boys and girls or between rural or urban residents

(Table2). The components of the index were: $\mathrm{ft}(0.2)$, $\mathrm{mt}(0.6)$ and $\mathrm{dt}(2.9)$.

The mean DMFT index in 9-yearolds was 0.9 overall, with no significant differences by sex or urban/rural residence (Table 3). The components of the index were: MT (0.02), FT (0.05) and DT (0.9).

The left/right incidences of caries was highest in the primary second molars in the mandible (47.9\%/49.1\%), followed by the primary first molars of the mandible (41\%/41.4\%). Among permanent teeth, lower first permanent molar had the highest caries incidence $(27.2 \% / 28.1 \%)$. For the lower incisors the values were: centrals $0 \% / 0 \%$; laterals $0.1 \% / 0 \%$, and canine teeth $0.1 \% / 0.1 \%$.

Mild or suspicious fluorosis was noticed in $4.9 \%$ of the children and severe fluorosis in $0.6 \%$.

\section{2-year-olds}

A total of 748 12-year-olds were examined. The mean DMFT index in children aged 12 years was 1.9. Girls had significantly higher DMFT (2.0) than boys $(1.7)(P<0.05)$ and DMFT values were significantly higher in urban than rural areas $(1.9$ versus 1.7$)(P<0.05)$. Mean DT, MT and FT values were 1.6, 0.1 and 0.2 respectively.

The first molar had the greatest left/ right caries incidence at $27.2 \% / 28.1 \%$ in the lower jaw, while incisors ( $0 \% / 0 \%$ and $0.1 \% / 0 \%)$ and the canine teeth $(0.1 \% / 0.1 \%)$ had the lowest caries rate.

Mild or suspicious fluorosis was noticed in $6.6 \%$ of the children and severe fluorosis was detected in $1.7 \%$.

\section{Caries-free rates}

Table 4 shows the proportion of children who were caries-free in the 4 age groups. Overall $48 \%$ of 3 -years-olds were caries-free: $42 \%$ of boys and $53 \%$ of girls $(P<0.05)$. Fewer rural children (41\%) than urban children (52\%) were caries-free $(P<0.05)$.

Of the children aged 6 years old, $11 \%$ were caries-free for both dentitions. Girls $(12 \%)$ were more significantly caries free than boys $(10 \%)(P<0.05)$. No

\begin{tabular}{|c|c|c|c|c|c|c|c|c|}
\hline \multirow{2}{*}{$\begin{array}{l}\text { Age group } \\
\text { (years) }\end{array}$} & \multirow[t]{2}{*}{ No. sampled } & \multicolumn{7}{|c|}{$\%$ of children caries-free } \\
\hline & & Total & Boys & Girls & Significance & Rural & Urban & Significance \\
\hline 3 & 750 & 48 & 42 & 53 & $P<0.05$ & 41 & 52 & $P<0.05$ \\
\hline 6 & 8725 & $11^{\mathrm{a}}$ & 10 & 12 & $P<0.05$ & 11 & 11 & NS \\
\hline 9 & 8723 & $10^{\mathrm{a}}$ & 9 & 11 & $P<0.05$ & 11 & 9 & $P<0.05$ \\
\hline 12 & 748 & $32^{\mathrm{a}}$ & 32 & 31 & NS & 35 & 29 & $P<0.05$ \\
\hline
\end{tabular}

${ }^{a}$ Both permanent and deciduous dentition.

$N S=$ not significant . 


\begin{tabular}{|c|c|c|c|c|c|c|c|c|}
\hline \multirow{2}{*}{$\begin{array}{l}\text { Age } \\
\text { group } \\
\text { (years) }\end{array}$} & \multirow{2}{*}{$\begin{array}{c}\text { No. } \\
\text { sampled }\end{array}$} & \multicolumn{7}{|c|}{ No. of teeth requiring treatment per 100 teeth } \\
\hline & & $\begin{array}{l}\text { Single-surface } \\
\text { filling }\end{array}$ & $\begin{array}{l}\text { Multi-surface } \\
\text { filling }\end{array}$ & $\begin{array}{l}\text { Stainless steel } \\
\text { crown }\end{array}$ & $\begin{array}{c}\text { Endodontic } \\
\text { therapy }\end{array}$ & Extraction & $\begin{array}{l}\text { Preventive } \\
\text { treatment }\end{array}$ & $\begin{array}{l}\text { Fissure- } \\
\text { sealant }\end{array}$ \\
\hline 3 & 750 & 72 & 49 & 1.2 & 7 & 1.4 & 130 & 10 \\
\hline 6 & 8725 & 87 & 141 & 7.7 & 39 & 67.0 & 115 & 45 \\
\hline 9 & 8723 & 90 & 69 & 3.3 & 20 & 72.0 & 107 & 42 \\
\hline 12 & 748 & 114 & 14 & 0.3 & 8 & 23.0 & 143 & 50 \\
\hline
\end{tabular}

statistically significant differences were found by sex or residence.

Among all studied 9-year-old children, $10 \%$ were caries-free for both dentitions; $11 \%$ of girls were caries-free compared with $9 \%$ for boys $(P<0.05)$. Also rural areas $(11 \%)$ had a significantly higher caries-free rate than urban areas $(9 \%)(P<0.05)$.

More than three-quarters of the children aged 12 years (78\%) were caries-free for deciduous teeth, $40 \%$ for permanent teeth and 32\% for both dentitions. The caries-free rate were not statistically different comparing girls and boys (31\% and 32\% respectively). The caries-free value was significantly higher in rural $(11 \%)$ than urban children $(9 \%)(P<0.05)$.

\section{Treatment needs}

Excluding preventive treatments, single surface filling was the highest treatment need of all age groups. In 6-year-olds, however, multisurface filling was the highest treatment need. Table 5 summarizes the treatment need findings for the 4 age groups.

\section{Discussion}

This nationwide survey showed that the mean $\mathrm{dmft} / \mathrm{DMFT}$ indices were 1.9/for 3-year-olds, 5.0/0.2 for 6-year-olds, 3.6/0.9 for 9-year-olds and 0.6/1.9 for 12-year-olds. Significant differences in dental caries prevalence were found according to sex, province, urban/rural residence, family income and parents' level of education.
We can compare our national data with other local surveys in the Islamic Republic of Iran. Meyer-Lueckel et al. during March to April 2003 examined 593 12- and 15-year-old children in 3 areas in the Islamic Republic of Iran which had varying degrees of urbanization and fluoride in piped water [12]. DMFT values were higher in the cities (1.2 and 1.5 in Tehran and Semnan respectively) than the rural village (0.7). In our survey, the mean DMFT of 12year-olds in the cities was only slightly higher than for the rural children (1.9 versus 1.7) and the difference was not significant, which may be due to the fact that our study sampled the whole country rather than just a few areas. Meyer-Lueckel et al. also conducted the same study on 5236-and 9-year-olds in the same cities and village and found comparable dmft rates and caries-free rates between the cities and village, despite differences in fluoridation of the water [13]. This is consistent with our findings that the DMFT values of 6- and 9-year-old children were not significantly different between rural and urban children.

Momeni et al. clinically examined dental caries in 1102 12-year-old children living in Tehran and a rural area outside Isfahan [5]. The overall mean DMFT was 0.77 . The rate of caries varied according to children's socioeconomic position. Rural children had significantly lower mean DMFT values (0.38) than children living in Tehran (1.10). The higher DMFT rate in cities in agreement with the findings of Meyer-Lueckel et al., although it should be noted that our data were not statistically significant. In the city of Tehran, Momeni et al. also found marked differences related to social status. The lowest DMFT values (0.74) were found in southern Tehran, where the people were classified in the lowest socioeconomic group. The highest caries index was found in the middle-class social stratum.

In an earlier survey in 1998-99 the percentage of caries-free (deciduous and permanent teeth) children among 6- and 9-year-olds in the Islamic Republic of Iran was $13.8 \%$ and $11.5 \%$ respectively [14]. This is supported by the findings of the present survey. The percentage of caries-free (deciduous and permanent teeth) children among 6- and 9-year-olds in our study was $11.2 \%$ and $10.0 \%$ respectively.

Daneshkazemi and Davari examined 1223 randomly selected 12-year-old students in junior high schools of Yazd and Hadi-Shahr of the Islamic Republic of Iran via a descriptive questionnaire-based study to determine the prevalence and distribution of DMFT and enamel hypoplasia [15]. The effect of occupational and educational levels of parents was also examined. The mean DMFT score was 1.8 and $28.6 \%$ of the 12 -year-olds were caries-free. This is relatively close to our national mean value of $32.0 \%$ of 12-year-old caries-free. Consistent with our results, DMFT was not significant associated with sex and parents' education or occupation level. The authors reported that the mean DMFT scores were higher than global standards according to $\mathrm{WHO}$ references for the year 2000 . 
(a) DMFT

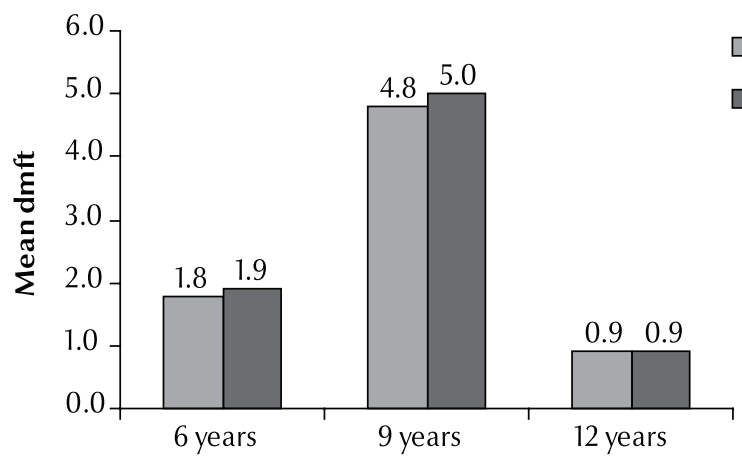

(b) DMFT

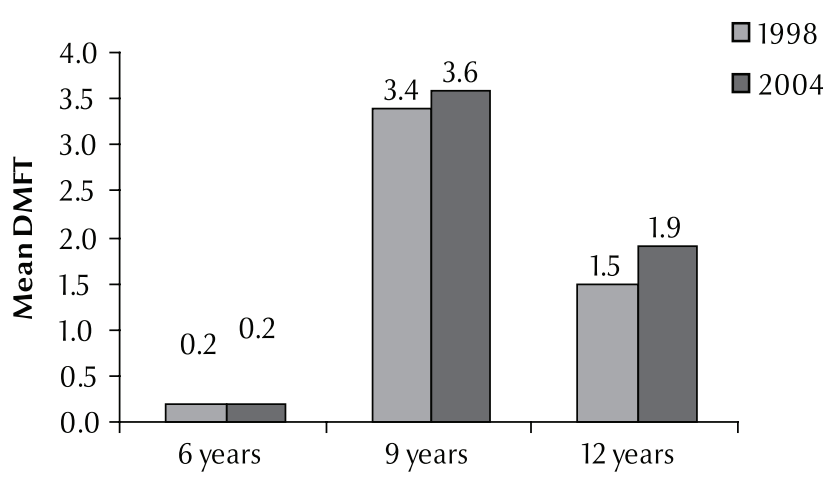

Figure 1 Comparison of the decayed/missing/filled teeth index in deciduous teeth (dmft) and permanent teeth (DMFT) of the 2 successive national pathfinder surveys of oral health in 1998 [14] and 2004 [current survey] in the Islamic Republic of Iran

Figure 1 shows a comparison between the 1998 national pathfinder survey [14] and the current survey in 2004. With similar or slightly higher $\mathrm{dmft} / \mathrm{DMFT}$ rates in the second survey in 2004 compared with the first national oral health survey in 1998, the figures demonstrate a lack of satisfactory progress towards the standard international values and reflect the old children were $1.8 /-$ and 4.8/0.2 in 1998. The marked difference of the dentition between 3-and 9-year-olds and also between 6-and 12-year-olds makes it unhelpful to track the alterations of mean $\mathrm{dmft} / \mathrm{DMFT}$ scores. These values were $3.6 / 0.9$ and $-/ 1.9$ for the same age group by 2004 . Therefore we can conclude that a 3-year interval between the 2 surveys would make it possible to track changes of caries indices in a given population, since the 6-year-olds of the former survey would be the 9-year-olds of the latter and the dentition of the 2 would not have gone through such extreme changes.

The aim of the present study was to provide a national baseline data on the oral health status of children in the Islamic Republic of Iran. Clearly to achieve and maintain a marked decline in DMFT scores, application of welloriented preventive national oral health programmes are essential.

\section{Acknowledgements}

ineffectiveness of the national oral health programmes in Islamic Republic of Iran.

Since the time interval between the 2 national surveys in 1998 and 2004 was 6 years, the cohort of children aged 3 and 6 years in the 1998 survey would be in the cohort aged 9 and 12 years in the present survey in 2004. The mean $\mathrm{dmft} / \mathrm{DMFT}$ scores of 3- and 6-year-
Our study was made possible through the combined efforts of a number of Iranian epidemiologists, researchers and dentists, the Ministry of Health and Medical Education of Islamic Republic of Iran, and the Science, Research and Technology Institute of Farzan, Department of Dentistry. We would also like to express our sincere gratitude to Dr M. Naghavi for the statistical work.

\section{References}

1. Al-Malik MI, Holt RD, Bedi R. Erosion, caries and rampant caries in preschool children in Jeddah, Saudi Arabia. Community Dentistry and Oral Epidemiology, 2002, 30:16-23.

2. Caban-Martinez AJ et al. Dental care access and unmet dental care needs among U.S. workers: the National Health Interview Survey, 1997 to 2003. Journal of the American Dental Association, 2007, 138:227-230.

3. Pakshir HR. Dental education and dentistry system in Iran. Medical Principles and Practice, 2003, 12(Suppl. 1):56-60.

4. Oral health surveys-basic methods, 4th ed. Geneva, World Health Organization, 1997.

5. Oral health status of Iranian children: 1995. National report of the Ministry of Health and Medical Education. Tehran, Islamic
Republic of Iran, Ministry of Health and Medical Education, 1995.

6. Hobdell M et al. Global goals for oral health 2020. International Dental Journal, 2003, 53(5):285-288.

7. Momeni A, Mardi M, Pieper K. Caries prevalence and treatment needs of 12-year-old children in the Islamic Republic of Iran. Medical Principles and Practice, 2006, 15:24-28.

8. Bourgeois D, Leclercq MH, Barmes D. Evaluation of the World Health Organisation pathfinder methodology for oral health surveys in industrialised countries. Community Dental Health, 1992, 9(4):381-384.

9. Kingman A, Selwitz RH. Proposed methods for improving the efficiency of the DMFS index in assessing initiation and 
progression of dental caries. Community Dentistry and Oral Epidemiology, 1997, 25(1):60-68.

10. Rozier RG. The prevalence and severity of enamel fluorosis in North American children. Journal of Public Health Dentistry, 1999, 59(4):239-246.

11. Lin HC, Schwarz E. Oral health and dental care in modernday China. Community Dentistry and Oral Epidemiology, 2001, 29(5):319-328.

12. Meyer-Lueckel $\mathrm{H}$ et al. Prevalence of caries and fluorosis in adolescents in Iran. Quintessence International, 2007, 38:459465.
13. Meyer-Lueckel $\mathrm{H}$ et al. Caries and fluorosis in 6- and 9-yearold children residing in three communities in Iran. Community Dentistry and Oral Epidemiology, 2006, 34:63-70.

14. Oral health situation of Iranian children 1998-1999, 1st ed. Tehran, Islamic Republic of Iran, Ministry of Health and Medical Education, Oral Health Bureau, 1999.

15. Daneshkazemi AR, Davari A. Assessment of DMFT and enamel hypoplasia among junior high school children in Iran. Journal of Contemporary Dental Practice, 2005, 6:85-92.

\section{Corrections}

B. Malekafzali, M. Biria, N. Tadayon and H. Abbasi. Comparison of plaque removal efficacy of new and 3-month-old toothbrushes in children. Eastern Mediterranean Health Journal, 2011, 17(2):115-120. On page 118, column 3 , line 19, " 0.3 " is incorrect and should read " 0.03 ".

Medication prescribing patterns in primary care in Riyadh city, Saudi Arabia. Eastern Mediterranean Health Journal, 2011 , 17(2):126-179.

In this series of papers, the name of the author M.A. Magzoub should read محي الدين على مجذوب in Arabic. 